\title{
ACMT Chelation Position Adopted by Oregon Medical Board
}

\author{
Brent T. Burton
}

Published online: 21 February 2014

(C) American College of Medical Toxicology 2014

The contributors to the Special Issue: Use and Misuse of Metal Chelation Therapy [1] have provided an excellent review and scientific analysis which clearly identifies the dichotomy between the appropriate versus erroneous indications and inappropriate diagnostic procedures for chelation therapy. This review further reinforces the 2009 American College of Medical Toxicology (ACMT) Position Statement [2].

Unfortunately, despite the lack of any scientific data that support chelation therapies for a broad range of claimed indications, the illegitimate chelation therapists continue to offer chelation treatments with ever increasing frequency. No amount of scientific persuasion is likely to reduce or eliminate this practice, which continues to present a significant public health problem by diverting medical resources and delaying or eliminating the opportunity to obtain appropriate medical evaluation and treatment. It is only with threat of licensing sanctions or adverse legal consequences that inappropriate chelation therapies can be curtailed.

Relying on the ACMT Position Statement, the Oregon Medical Board (OMB) has recently launched an assault on illegitimate chelation clinics with the publication of a "Statement of Philosophy" regarding chelation therapy. This statement first acknowledges that "there is no scientific evidence that chelation therapy is an effective treatment for any medical condition other than heavy metal toxicity." The OMB also takes aim specifically at the "post-chelator challenge," which is characterized as a test that "does not meet the standard of care for diagnosis of heavy metal toxicity" [3].
Because illegitimate chelation therapists infrequently come to the attention of state licensing boards, it has become the responsibility of OMB licensees to identify and (anonymously) report other licensees who engage in unprofessional conduct defined by law as "repeated ordering or performance of unnecessary laboratory tests or radiologic studies; administration of unnecessary treatment; employment of outmoded, unproved or unscientific treatments." Reporting is not just an option, but a requirement under Oregon law, although a licensee making a report in good faith is immune from civil liability [4].

With the exception of Oregon, neither the Federation of State Medical Boards (FSMB) nor any individual state medical board has specifically condemned the practice of chelation therapies for unapproved indications and improper diagnostic methods. Every state medical board should be encouraged to follow Oregon's example.

\section{References}

1. Special Issue: Use and Misuse of Metal Chelation Therapy. J. Med. Toxicol. (2013) 9 (4)

2. ACMT Position Statement on Post-Chelator Challenge Urinary Metal Testing. July 27, 2009

3. Oregon Medical Board (2013) Statements of philosophy: chelation therapy. http://www.oregon.gov/omb/board/philosophy/Pages/ Chelation-Therapy.aspx Accessed 15 Jan 2014

4. Oregon Revised Statutes (ORS) 676.150

B. T. Burton $(\bowtie)$

Beaverton, OR, USA

e-mail: occtoxdoc@msn.com 